\title{
COMPOSTAGEM DE LODO DE ESGOTO SOB A PERSPECTIVA DA ECONOMIA REGENERATIVA EM PEQUENOS MUNICÍPIOS
}

\author{
${ }^{1}$ Milena Lima Brandão; ' Luciano Matos Queiroz \\ 1Universidade Federal da Bahia; Salvador/BA; milenalbrandao@gmail.com \\ 2Universidade Federal da Bahia; Salvador/BA; Imqueiroz@ufba.br
}

Resumo: Este trabalho avaliou o processo de compostagem de lodo de esgoto como técnica de valorização e promoção dos preceitos da economia regenerativa. A pilha de compostagem foi montada com lodo anaeróbio, serragem como estruturante e resíduos de frutas e vegetais como aditivo do processo. A pilha foi revolvida manualmente e o processo foi monitorado por medição da temperatura e análises de parâmetros microbiológicos e de metais. Os resultados obtidos evidenciaram que as concentrações dos patógenos e substâncias inorgânicas estavam abaixo dos limites estabelecidos na Resolução CONAMA 375/06. Concluiu-se que a compostagem do lodo possibilita a reciclagem de nutrientes e valoriza o lodo de esgoto evitando a disposição em aterros sanitários e seus consequentes impactos ambientais.

Palavras-Chave: Compostagem; Lodo de esgoto; Valorização

\section{COMPOSTING OF SEWAGE SLUDGE FROM THE PERSPECTIVE OF THE REGENERATIVE ECONOMY IN SMALL MUNICIPALITIES}

\begin{abstract}
This work evaluated the sewage sludge composting process as a technique for valuing this waste and promoting the precepts of the circular and regenerative economy. Composting was conducted in a pile assembled with anaerobic sludge, sawdust as a bulking agent and food waste (fruits and vegetables) as process additive. The pile was manually revolved and the process was monitored by temperature measurement and analysis of microbiological parameters and metal concentration. The results showed that the concentrations of pathogens and inorganic substances were below the limits established in Brazilian standards. It was concluded that the composting of the sludge enables the recycling of nutrients and enhances the sewage sludge avoiding the disposal in landfills and its consequent environmental impacts.
\end{abstract}

Keywords: Composting; Sewage sludge; Valorization 


\section{INTRODUÇÃo}

Os sistemas descentralizados de tratamento de esgoto são aqueles que coletam, tratam e fazem a disposição final ou reúso do esgoto em local próximo à sua geração. São alternativas atrativas para garantir a saúde da população e ao mesmo tempo manter a integridade ambiental dessas localidades, especialmente em áreas esparsamente habitadas. Considerando que, aproximadamente, $70 \%$ dos municípios brasileiros tem população menor que 20 mil habitantes [1], a escolha da tecnologia de tratamento deve levar em consideração os desafios sociais e técnicos existentes.

Os processos de tratamento de esgoto geram em suas diversas etapas lodos com características e volumes variáveis. O gerenciamento do lodo de esgoto é uma atividade complexa e de alto custo, podendo representar cerca de $50 \%$ dos custos operacionais de uma estação de tratamento de esgotos (ETE) [2].

O lodo proveniente de ETE é classificado pela NBR 10.004/2004 (ABNT, 2004) como resíduo sólido visto que que não pode ser disposto na rede pública de esgotamento sanitário e nos corpos d'água ou exige soluções técnicas ou economicamente inviáveis em face da melhor tecnologia disponível [3].

A Política Nacional de Resíduos Sólidos (PNRS), instituída pela Lei Federal $12.305 / 2010$ prevê que os resíduos sólidos devem passar por todas as possibilidades de tratamento e recuperação por processos tecnológicos disponíveis e economicamente viáveis, para que ao fim desses processos o rejeito gerado tenha sua disposição final ambientalmente adequada [4]. Contudo, no Brasil, a principal destinação final do lodo oriundo das ETE é o aterro sanitário [5], medida que não permite a valorização desses resíduos, sobretudo, 0 aproveitamento dos macronutrientes (nitrogênio, fósforo e potássio) presentes nos lodos de esgoto em elevadas concentrações.

A compostagem é uma técnica que permite destinação adequada sendo relativamente simples, com baixo custo de implantação e eficiente para a redução da concentração de microrganismos patogênicos no lodo. Resulta desse processo biológico aeróbio um composto estabilizado com potencial para uso agrícola desde que atendida a legislação ambiental vigente, pois o lodo tem alto teor de matéria orgânica o que promove melhorias nas características físico-químicas do solo.

Esse potencial agrícola pode agregar para o agronegócio brasileiro que representa uma parcela significativa da economia do país. O setor consumiu 34 mil toneladas de fertilizantes no ano de 2017 sendo que desse total, 75\% foi importada [6]. Essa dependência externa eleva os custos das lavouras. A valorização de resíduos do setor de saneamento como composto ou água de reúso poderia reduzir uma parcela desses custos fixos ajudando a aumentar o valor agregado de produtos brasileiros no mercado externo.

Kiehl [7] afirma que o uso de fertilizantes orgânicos, como os oriundos do lodo, em comparação como uso de fertilizantes minerais apresenta liberação lenta dos seus nutrientes de forma a fornecer continuamente suprimento desses elementos às plantas. Por outro lado, os componentes dos adubos químicos podem ser facilmente lixiviados para áreas mais profundas das zonas das raízes, impedindo o seu uso integral pelas plantas e podendo contaminar os recursos hídricos.

Porém, o atendimento dos critérios preconizados na Resolução CONAMA 375, publicada no ano de 2006 [8], ainda constitui um desafio para a implantação segura 


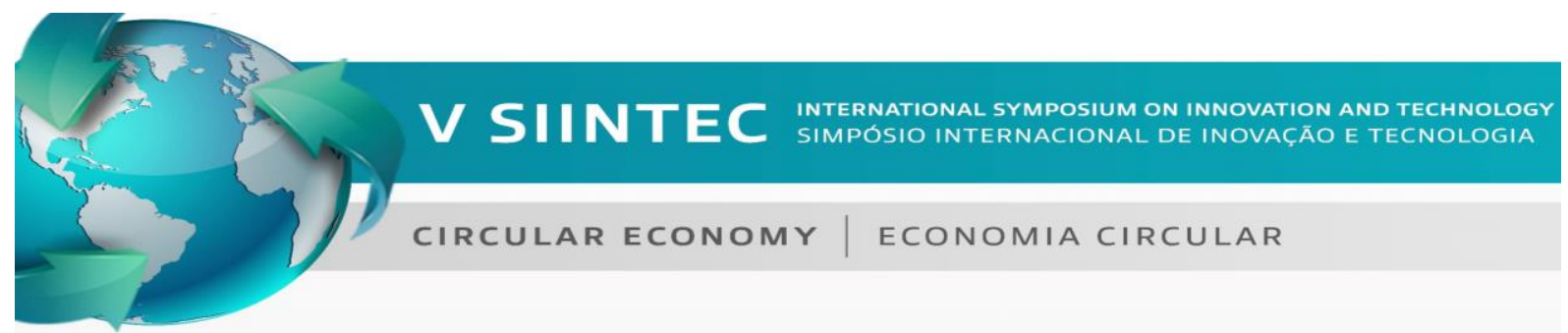

da técnica de compostagem de lodos de esgoto. Desafios do processo, como, por exemplo, a manutenção da temperatura adequada que garanta a inativação de microorganismos patogênicos ou a redução do tempo de maturação do composto demandam iniciativas inovadoras na montagem e manejo de pilhas e leiras. Esses desafios tornam-se mais complexos quando se considera o cenário de gestão de resíduos sólidos e manejo de águas residuárias em municípios brasileiros de pequeno porte.

Diante da crescente demanda por alternativas que sejam viáveis econômico e ambientalmente para disposição do lodo, o objetivo desse trabalho foi avaliar o processo de compostagem com base na Resolução CONAMA 375/2006 como forma de agregar valor ao lodo de esgoto em pequenas comunidades promovendo uma economia regenerativa e fechamento do ciclo biogeoquímico de macronutrientes.

\section{METODOLOGIA}

A organização de feiras livres e presença de mercados populares é comum em municípios baianos de pequeno porte. Essas feiras são organizadas em um determinado dia da semana e, ao término das atividades, a geração de resíduos é inevitável. Portanto, a metodologia foi concebida buscando uma visão integrada de valorização de resíduos. Buscou-se a possibilidade da valorização concomitante de resíduos de feiras livres e lodo de esgoto por meio do processo de compostagem. $O$ arranjo se justifica, na medida em que se espera uma dificuldade da compostagem de lodo anaeróbio digerido, sobretudo, no que concerne ao atendimento de critérios de manutenção de temperaturas elevadas das pequenas pilhas durante intervalo de tempo superior a 8 (oito) dias.

Para avaliar a possibilidade de implantação do processo de compostagem de lodo em pequenas estações de tratamento de esgotos sanitários, realizou-se um estudo utilizando o lodo anaeróbio gerado por uma população estimada em 1.100 habitantes. A pilha de compostagem formada por lodo, serragem (madeira não tratada) e resíduo de alimentos (frutas e vegetais) coletados manualmente dos galpões de feiras livres foi montada no galpão do Laboratório de Resíduos e Efluentes número 4 (LABEXAN 4) localizado na Escola Politécnica da Universidade Federal da Bahia. O volume de lodo e serragem utilizados foram iguais a 245 litros e adicionou-se 78 quilogramas de resíduos de alimentos. A escolha pela proporção 3:3:1 lodo/estruturante/resíduo se justifica pela elevada umidade do lodo utilizado, e os resíduos contribuem para não reduzir a atividade biológica da mistura.

O processo foi monitorado por meio da medição diária da temperatura utilizando termômetro digital e para quantificação dos parâmetros microbiológicos, foram realizadas análises quinzenais de coliformes totais e ovos viáveis de helmintos conforme o método 9223 do Standard methods for the examination of water and wastewater [9].

Ao fim do processo, o composto final foi peneirado e foram medidos o volume e o peso final do material retido e peneirado da pilha. Além disso, alíquotas do composto peneirado foram submetidas a análises físico-química de caracterização por extração simples e de espectrofotometria de absorção atômica nas dependências do laboratório Eco System Preservação do Meio Ambiente LTDA®. Analisaram as 
concentrações dos metais arsênio, cádmio, chumbo, cobre, cromo, mercúrio, molibdênio, níquel e zinco em triplicata.

\section{RESULTADOS E DISCUSSÃO}

O perfil de temperatura da pilha ao longo do processo é mostrado na Figura 1.

Figura 1. a) Perfil de temperatura da pilha. b) Destaque da fase termofílica

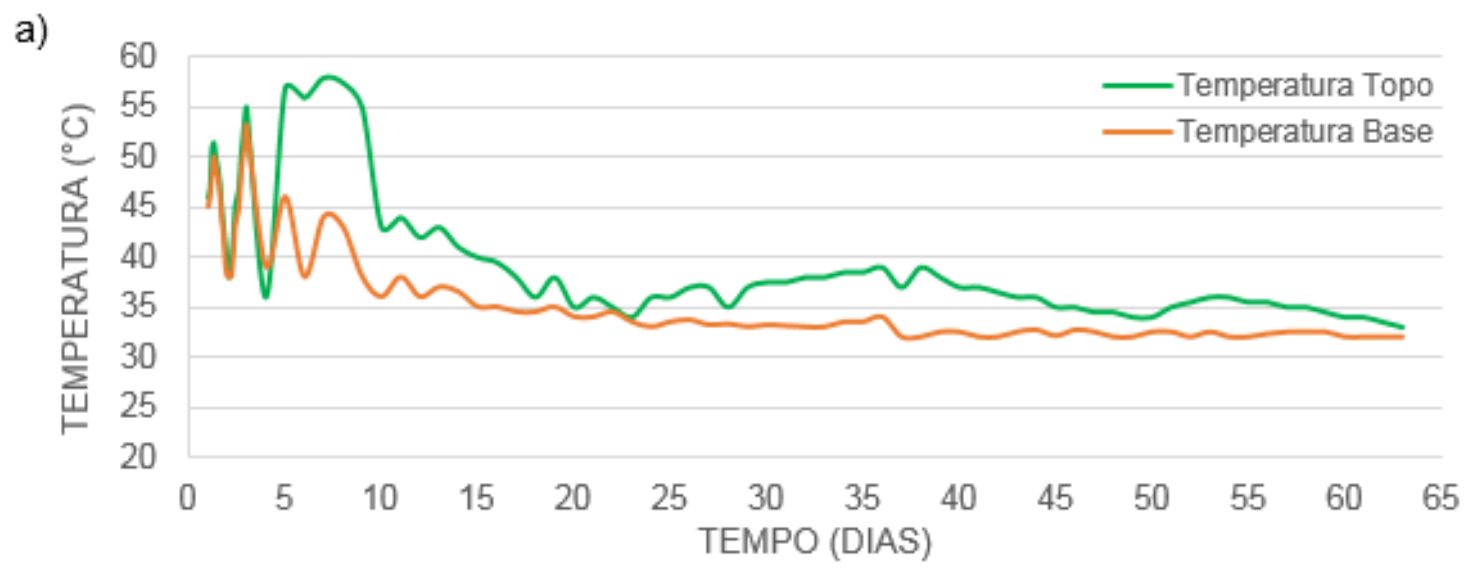

b)

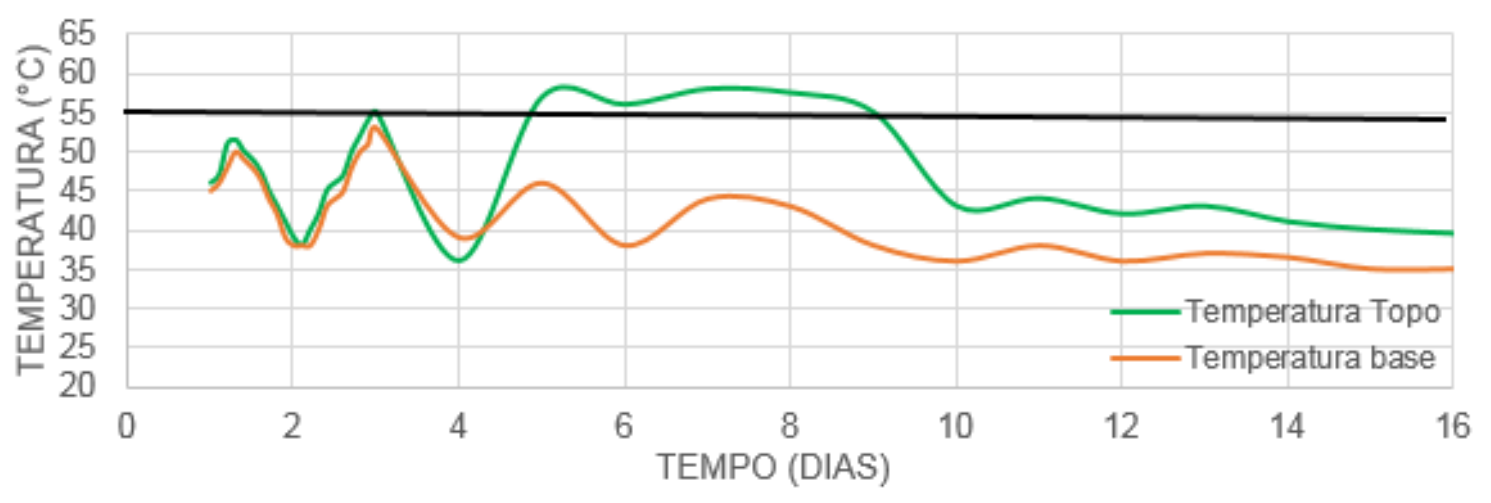

Fonte: Própria Autora

Constata-se que o processo atingiu a fase termofílica $\left(55^{\circ} \mathrm{C}\right)$ com pico de temperatura igual a $58^{\circ} \mathrm{C}$ no topo da pilha atestando o sucesso da inserção de resíduos de alimentos no processo de compostagem do lodo de esgoto anaeróbio. Por outro lado, na base da pilha, a maior temperatura alcançada foi igual a $53^{\circ} \mathrm{C}$. Essa diferença de temperatura era esperada, visto que outros trabalhos afirmam que no topo da pilha há fornecimento melhor de oxigênio e é o ponto de conversão de calor [10]. Esses autores também destacam a importância do revolvimento regular para garantir o acesso ao topo da pilha e assim o contato com temperaturas mais elevadas.

Dessa maneira, durante a fase termofílica, o revolvimento da pilha foi praticamente diário a fim de permitir o contato de várias partes da pilha com temperaturas mais elevadas, além de permitir um maior fornecimento de oxigênio. 
Observando o atendimento dos critérios preconizados na Resolução CONAMA 375/06, para uso agrícola, o lodo de esgoto deve passar por processo de redução significativa de patógenos. Para ser classificado como Classe $\mathrm{B}$, a massa de resíduos que compõe a pilha ou leira de compostagem tem que atingir uma temperatura mínima de $40^{\circ} \mathrm{C}$, durante pelo menos cinco dias consecutivos, com a ocorrência de um pico de $55^{\circ} \mathrm{C}$, ao longo de quatro horas sucessivas durante esse período. Para ser classificado como Classe $A$, os critérios são mais restritivos. No processo de compostagem de pilhas revolvidas, esse período deve ser igual a 15 dias sob temperatura mínima igual a $5^{\circ} \mathrm{C}$. Além, da necessária redução da atratividade de vetores, na qual a temperatura da massa de resíduos deve ser mantida acima de $40^{\circ} \mathrm{C}$ por pelo menos 14 dias e temperatura média durante este período deve ser maior que $45^{\circ} \mathrm{C}[8]$.

Considerando esses critérios, como pode ser observado na Figura 1 b), o processo alcançou temperatura igual a $40^{\circ} \mathrm{C}$ durante pelo menos 5 dias, com ocorrência de um pico de 58으. Adicionalmente, observa-se que, também, foi obedecido o critério para evitar a atratividade de vetores. Porém, o processo não foi capaz de garantir o atendimento dos critérios para produção de composto classe $A$. Esse fato, provavelmente, está associado ao volume da pilha $\left(0,5 \mathrm{~m}^{3}\right)$.

Os resultados das análises das concentrações de indicadores bacteriológicos e microrganismos patogênicos estão mostrados na Tabela 1. Pode-se observar que todos os indicadores estão dentro dos limites estabelecidos pela Resolução 375/06 do CONAMA, o que confirma que a compostagem conjunta com resíduos de alimentos é uma técnica eficaz para a sanitização do lodo de esgoto.

Tabela 1. Resultado da sanidade do material peneirado e limites da Resolução CONAMA

\begin{tabular}{|c|c|c|}
\hline $\begin{array}{c}\text { Indicadores } \\
\text { bacteriológicos e } \\
\text { agentes patogênicos }\end{array}$ & $\begin{array}{c}\text { Limite Resolução } \\
\text { CONAMA 375/2006 }\end{array}$ & $\begin{array}{c}\text { Composto } \\
\text { final }\end{array}$ \\
\hline $\begin{array}{c}\text { Ovos viáveis de helmintos (ovos / } \\
\text { g de ST) }\end{array}$ & $<0,25$ (Classe A) \\
\hline $\begin{array}{c}\text { Coliformes termotolerantes } \\
\text { (NMP/g de ST) }\end{array}$ & $<10$ (Classe B) & $<0,25$ \\
\hline
\end{tabular}

Fonte: Própria Autora

Com base na Resolução Conama 375/06 o composto obtido no experimento levando em consideração apenas as concentrações de Escherichia coli e coliformes termotolerantes seria classificado como composto Classe B.

Entretanto, o uso agrícola do composto Classe B foi banido após 5 anos da publicação da Resolução 375/06. Porém, não há nenhuma justificativa técnica para essa medida. Alguns pesquisadores afirmam que o simples banimento do uso de composto classe B é uma medida rigorosa e que seu uso parece defensável, desde que acompanhado de medidas adequadas de proteção à saúde, com especial atenção à saúde ocupacional [11]. 
Os fatores que exercem influência na sobrevivência dos patógenos vão além de temperatura e tempo de exposição que as regulamentações nacionais e internacionais se baseiam. [12] afirma que a inativação da $E$. coli não é meramente dependente da temperatura, mas também é afetado pelo teor de umidade e pela natureza do material. Sendo assim necessário ser revisados para ser melhor discutidos e possivelmente alterados, complementados ou ajustados, de modo a permitir que as normas atendam efetivamente aos propósitos almejados.

Os resultados da concentração de metais (Tabela 2) estão muito abaixo do limite proposto pela Resolução do CONAMA o que já era esperado, pois se trata de lodo oriundo do tratamento de esgoto doméstico de uma ETE de pequeno porte, com uma rede coletora pequena e que dificilmente receberá contribuição de efluentes de constituição complexa.

Tabela 2. Resultado das substâncias inorgânicas do material peneirado e limites da Resolução CONAMA 375/2006.

\begin{tabular}{|c|c|c|}
\hline $\begin{array}{c}\text { Substâncias } \\
\text { inorgânicas (mg/kg, } \\
\text { base seca) }\end{array}$ & $\begin{array}{c}\text { Limite Resolução CONAMA } \\
375 / 2006\end{array}$ & $\begin{array}{c}\text { Composto } \\
\text { final }\end{array}$ \\
\hline Arsênio & 41 & - \\
\hline Bário & 1300 & $2,39 \pm 0,24$ \\
\hline Cádmio & 39 & $<5 \times 10^{-3}$ \\
\hline Chumbo & 300 & $296 \pm 24$ \\
\hline Cobre & 1500 & $18,76 \pm 1,23$ \\
\hline Cromo & 1000 & $<2 \times 10^{-4}$ \\
\hline Mercúrio & 17 & $23,67 \pm 4,00$ \\
\hline Molibdênio & 50 & $21,85 \pm 3,17$ \\
\hline Níquel & 420 & - \\
\hline Selênio & 100 & $809 \pm 28$ \\
\hline Zinco & 2800 & \\
\hline
\end{tabular}

Fonte: Própria Autora

Outra importante questão para a ampla utilização da técnica é o custo dessas análises físico-químicas de monitoramento. O acompanhamento das características do lodo de esgoto ou produto derivado proposto pela Resolução 375/2006 de acordo com os critérios de frequências para aplicação agrícola deve ser anual e feita por meio de análise de 4 (quatro) amostras simples, coletadas com defasagem mínima de 7 (sete) dias em quadriplicada. $O$ atendimento desses critérios em municípios de pequeno porte localizados no interior do país e sem acesso aos laboratórios qualificados é muito difícil. Defende-se o exposto no art. 8 da Resolução 375/2006 que 
prevê a flexibilização por meio da alteração da lista de compostos e substâncias analisadas de acordo com as características da bacia de esgotamento sanitário.

\section{CONCLUSÃO}

Os resultados apresentados no presente trabalho demostram que a compostagem com a incorporação de substrato rapidamente degradável é uma técnica eficaz para valorização do lodo de esgoto. Os valores obtidos nas análises de microbiologia patogênica do composto final mostraram que o composto possui concentração de coliformes termotolerantes e ovos viáveis de helmintos abaixo do limite mais restritivo da legislação.

O volume da pilha de compostagem influencia na classificação do produto final, pois para atendimento dos critérios de garantia da segurança microbiológica do composto previstos na Resolução CONAMA 375/06 deve-se observar o binômio temperatura/tempo e, nas pilhas com volume reduzido é difícil manter temperaturas altas por longo período de tempo.

As análises das substâncias inorgânicas listadas na resolução CONAMA 375/06 mostraram que o composto possui concentração abaixo do limite para todas as seguintes substâncias analisadas: arsênio, cádmio, chumbo, cobre, cromo, mercúrio, molibdênio, níquel e zinco.

Assim, a implementação do processo de compostagem para aproveitamento agrícola do composto gerado frente aos resultados obtidos se mostra promissor deste que as particularidades locais sejam levadas em consideração.

\section{REFERÊNCIAS}

${ }^{1}$ IBGE - Instituto Brasileiro de Geografia e Estatística. Estimativas da População. Disponível em: https://www.ibge.gov.br/estatisticasnovoportaL/sociais/populacao/9103?=\&t=resultados. Acesso em: 17 de julho de 2019.

2 KACPRZAK M. et al. Sewage sludge disposal strategies for sustainable development. Journal of Environmental Research, v. 156, p. 39-46, 2017.

3 ASSOCIAÇÃO BRASILEIRA DE NORMAS TÉCNICAS. NBR 10004: Resíduos Sólidos: classificação. Rio de Janeiro, 2004.

${ }^{4}$ BRASIL. Lei № 12.305, de 02 de agosto de 2010. Institui a Política Nacional de Resíduos Sólidos altera a Lei no 9.605, de 12 de fevereiro de 1998; e dá outras providências. Brasília, 2010.

5 IBGE- Instituto Brasileiro de Geografia e Estatística. Pesquisa Nacional de Saneamento Básico 2008. Rio de Janeiro, 2010. Disponível em: < https://biblioteca.ibge.gov.br/visualizacao/livros/liv45351.pdf> Acesso em: 18 de julho de 2019. 
6 IPNI - International Plant Nutrition Institute. Aumento relativo de fertilizantes Brasil $x$ Mundo. Disponível em: < http://brasil.ipni.net/article/BRS3132\%23evolucao>. Acesso em: 18 de julho de 2019.

${ }^{7}$ KIEHL, E.J. Novo fertilizantes orgânicos. 1 ed. Edição do autor. Piracicaba/SP, 2012.

${ }^{8}$ BRASIL. Ministério do Meio Ambiente. Resolução CONAMA no 375, de 29 de agosto de 2006. Define critérios e procedimentos, para uso agrícola de lodos de esgoto gerados em estações de tratamento de esgoto sanitário e seus produtos derivados, e dá outras providências. Diário Oficial da República Federativa do Brasil. 2006.

9 AMERICAN PUBLIC HEALTH ASSOCIATION (APHA); AMERICAN WATER WORKS ASSOCIATION (AWWA); WATER ENVIRONMENTAL FEDERATION (WEF). Standard methods for the examination of water and wastewater. 22. ed., Washington, APHA/AWWAMEF, 2012.

10 INSAM, H.; DE BERTOLDI, M. Microbiology of the composting process. Compost Science and Technology, p. 25-48, 2007.

11 BASTOS, R. K. X. et al. Análise crítico-comparativa das regulamentações brasileira, estadunidense e britânica de qualidade microbiológica de biossólidos para uso agrícola. Revista DAE, v. 191, p. 10-20, 2013.

12 TURNER, C. The thermal inactivation of $E$. coli in straw and pig manure. Bioresource Technology, v. 84, n. 1, p. 57-61, 2002. 